\title{
e-PADI: An IoT-based paddy productivity monitoring and advisory system
}

\author{
M.A.F. Ismail ${ }^{1}$, M. N. Md. Isa ${ }^{2}$, S. N. Mohyar ${ }^{3}$, M.I.Ahmad ${ }^{4}$, M. N. M. Ismail ${ }^{5}$, R. C. Ismail ${ }^{6}$, \\ A. Harun ${ }^{7}$ S.A.Z Murad ${ }^{8}$ \\ ${ }_{1,2,3,6,7,8}$ School of Microelectronic Engineering, Universiti Malaysia Perlis, Pauh Putra Campus, Malaysia \\ ${ }^{4}$ School of Computer and Communication Engineering, Universiti Malaysia Perlis, Pauh Putra Campus, Malaysia \\ ${ }^{5}$ Centre of Diploma Studies, Universiti Malaysia Perlis, UniCITI Alam Campus, Malaysia
}

\begin{tabular}{|c|c|}
\hline Article Info & ABSTRACT \\
\hline Article history: & Rice is source of food calories and protein. This second most widely grown \\
\hline Received Sep 27, 2018 & $\begin{array}{l}\text { cereal crop is the staple food for more than half the world's population } \\
\text { especially in developing countries. The ability of global rice production to }\end{array}$ \\
\hline Revised Nov 26, 2018 & meet population demands (now estimated at more than 5 billion and \\
\hline Accepted Dec 7, 2018 & $\begin{array}{l}\text { projected to rise to } 8.9 \text { billion by } 2050 \text { ) remains in uncertainty in the near } \\
\text { future unless challenges in rice production are properly addressed [1-3]. This }\end{array}$ \\
\hline Keywords: & $\begin{array}{l}\text { paper proposed an IoT (Internet of things)-based paddy productivity } \\
\text { monitoring and advisory system Using Dash7 Wireless Network Protocol. }\end{array}$ \\
\hline e-PADI & All collected data will be stored in a database management system to enable \\
\hline Internet of things & $\begin{array}{l}\text { users to retrieve data either from tablets, smartphones or computers. The } \\
\text { heart of the system is the ATmega } 328 \mathrm{p} \text { microcontroller that will control the }\end{array}$ \\
\hline Microcontroller & payload of the wireless network of dash7 and read data from sensor nodes. \\
\hline Wireless sensor networks & $\begin{array}{l}\text { Results show all data from sensor nodes in representation of graph for } \\
\text { analysis purpose. }\end{array}$ \\
\hline
\end{tabular}

Copyright $@ 2019$ Institute of Advanced Engineering and Science. All rights reserved.

\section{Corresponding Author:}

Mohd Nazrin Md Isa,

School of Microelectronic Engineering,

Universiti Malaysia Perlis,

Pauh Putra Campus, 02600 Arau, Perlis, Malaysia.

Email: nazrin@unimap.edu.my

\section{INTRODUCTION}

The e-PADI is an IoT-based paddy field monitoring and advisory system. It aims to increase farmers' paddy productivity by means of measuring paddy environments parameters in real-time. Table 1 summarizes the existing worldwide IoT-based system in agriculture sectors.

The use of an Internet of Things-based electronic system in agriculture especially in paddy monitoring has been extensively studied and developed since 2008 to date. The proposed system continues others work as reported in literature. New features or contribution of this work is that, the system is integrated with advisory system Using Dash7 Wireless Network Protocol [9-12]. Figure 1 shows the growing stage of typical paddy tree and their greenness. Most of the developed IoT-based system in literature monitor paddy development within the three stages; i.e.: the vegetative, reproductive and ripening stages. 
Table 1. IoT Applications in Agriculture

\begin{tabular}{ll}
\hline \multicolumn{1}{c}{ IoT applications in Agriculture } & \multicolumn{1}{c}{ Description } \\
\hline & Phase: Pre-harvesting and monitoring \\
E-KAKASHI (Japan) & Technology: Sensor gadgets, cloud database system \\
2011 [4] & Area: Farming productivity improvement and reduction of vermin damage \\
& Phase: Pre-harvesting \\
AGRO-SENSE (India) & Technology: Wireless sensor network, LR-WPAN technology \\
2008 [5] & Area: Control decision making \\
Precision agriculture irrigation system & Phase: Post-harvesting (irrigation) \\
(China) 2012 [6] & Technology: WSN, Fine Valve tube switches and irrigation pipes, GPRS. \\
& Area: Reduction in water consumption for irrigation. \\
Agriculture Machinery Intelligent & Phase: Post-harvesting \\
Scheduling in cross-regional work & Technology: Cloud computing, GPS. \\
(China)2010 [7] & Area: Agri resource management \\
Automated crop-disease Advisory & Phase: Pre-harvesting \\
Service (India) & Technology: wisekar, an internet of things repository system, image processing. \\
2016 [8] & Area: crop-disease advisory system \\
\hline
\end{tabular}

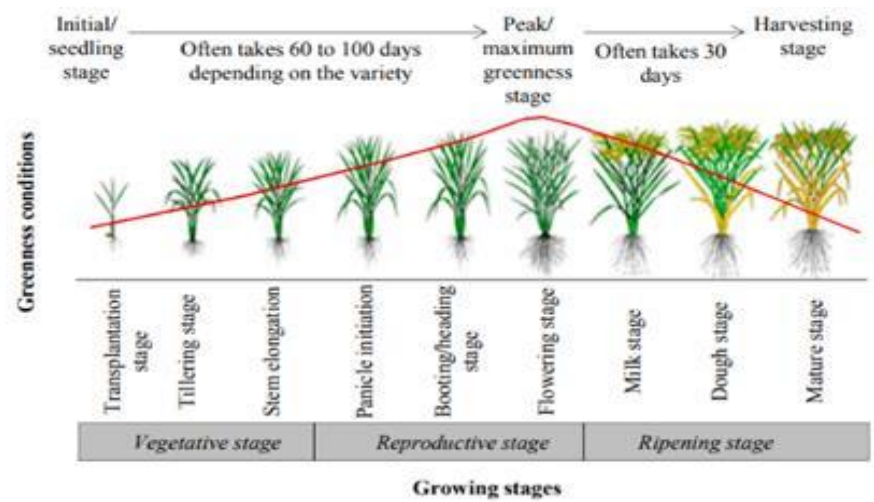

Figure 1. Growing stage of a typical paddy tree and their associated greenness [13]

\section{RESEARCH METHOD}

The e-PADI system comprises of sensor nodes, which can be deployed in the paddy field, whereas the measured data in the paddy field can be monitored and analyzed remotely from user application software in the smartphone. The wireless system is established by the e-PADI system gateway as shown in Figure 2. The system continuously monitors the status of the paddy development. It aims to increase paddy productivity by means of continuous monitoring paddy development from the seedling stage until the paddy ripening stage using IoT-based electronic system/kit. Advisory report will also be generated during the monitoring period, whenever required. The developed system can also be used to measure water level/soil acidity during pre or post-harvesting period.

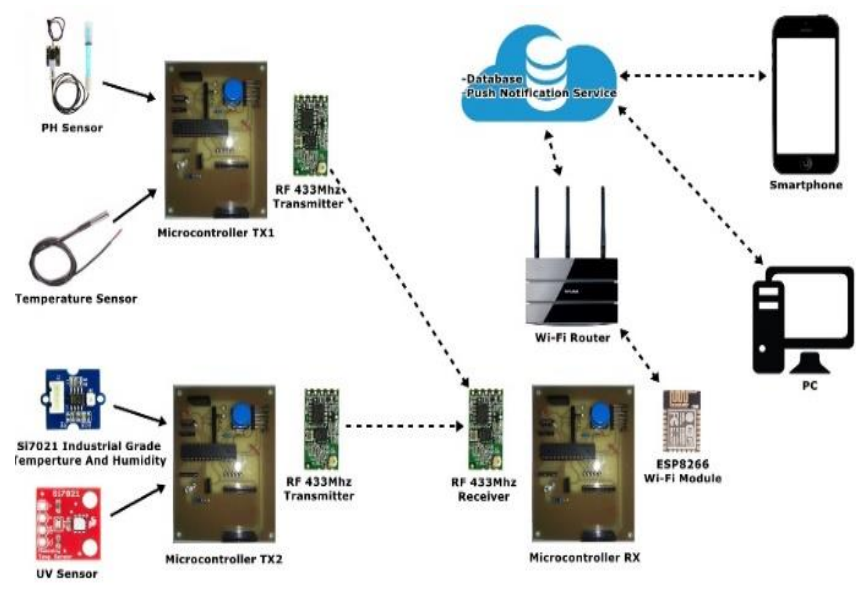

Figure 2. The e-PADI system 
The overall system illustration in Figure 2 shows the e-PADI consists of two transmitters and one receiver, each transmitter is connected with different types of sensors and receiver. All sensor nodes are connected via a wireless sensor network gateway. A star wireless network is used as the main network topology, thus enabling many transmitters from various sensor nodes transmitting information to the receiver. Details of each element in the system will be discussed in the following sections.

\subsection{The Sensor Nodes}

Sensor nodes help the system to measure environment parameters such as temperature, soil $\mathrm{PH}$, water levels in the paddy fields and many more. Each node has a microcontroller unit. The microcontroller collects measured data from the sensor nodes and passes it to the transmitter. Details of each sensor node and its description is summarized in Table 2.

Table 2. The e-PADI Sensor Nodes and Descriptions

\begin{tabular}{|c|c|}
\hline Sensor & Descriptions \\
\hline $\begin{array}{l}\text { Si7021 } \\
{[14]}\end{array}$ & $\begin{array}{l}\text { An industrial grade temperature and humidity sensor with higher rate accuracy as compared to the DHT11 } \\
\text { temperature sensor. The internal circuit consist of monolithic CMOS IC integrated, analog to digital converter, } \\
\text { signal processing, calibration data, and using i } 2 \mathrm{c} \text { interface. }\end{array}$ \\
\hline $\mathrm{PH}[15]$ & $\begin{array}{l}\text { PH Sensor determines the level of acidity or alkalinity of the water. The sensor will give the output in analog value } \\
\text { and the Atmega328p will read the analog value and by using the averaging method to smooth out the PH value. } \\
\text { According to MADA, the PH level in water must be around } 5.5 \text { to } 6.5 \text { that is ideal PH level for paddy planting. }\end{array}$ \\
\hline DSB18B20 & DSB18B20 temperature sensor use one wire communication to communicate with microcontroller and each \\
\hline [16] & $\begin{array}{l}\text { DSB18B20 has their specific address to communicate with microcontroller. Temperature of water will affect the } \\
\text { chemical and biological characteristic of the paddy plantation. It mainly affect the level of dissolved oxygen in the } \\
\text { paddy field. }\end{array}$ \\
\hline BH1750 & Light Intensity Sensor \\
\hline [17] & $\begin{array}{l}\text { BH1750 light intensity sensor that measure the level of light reflection in certain area. The sensor use I2C bus to } \\
\text { communicate with microcontroller, perfect to measure the level of sunlight in paddy field whether it is sunny or } \\
\text { cloudy. The light intensity sensor will determine how change of UV level from sunlight will affect the paddy } \\
\text { productivity. This sensor data will be used as analysis part. }\end{array}$ \\
\hline HCSR04 & Ultrasonic Sensor as Water Level Sensor \\
\hline [18] & $\begin{array}{l}\text { The common ultrasonic has one transmitter that called trigger and receiver one that called echo. It will measure the } \\
\text { water level at the irrigation inlet of the paddy field. This water level part is important when it comes to paddy } \\
\text { scheduling like planting and harvesting phase, the water level needs to be different for each phase. }\end{array}$ \\
\hline
\end{tabular}

\subsection{The Gateway}

The gateway comprises of the HC12 RF Module. This RF module operates at $433 \mathrm{MHz}$ and this module is crucial as to enable wireless communication between sensor nodes to the receiver. This RF module consist of two transmitter and one receiver and each of them communicate via dash7 network protocol. The communication protocol is similar to the well-known ZigBee protocol, however with added advantage of lower cost and better communication (simultaneous communication between transmitter and receiver) as compared to ZigBee. The channel and address of the transmitter and receiver must be identical. The star network topology can be easily established by changing the channel of the system.

\subsection{Sensor Node 1}

Sensor Node 1 consists of PH sensor, temperature and humidity sensor and luminosity sensor. Each of the sensor value returned in value of a float. Using the state machine procedure as illustrated in Figure 3(a), each of the sensors is read state by state until the last sensor.

Then, each of the sensor value is converted into string for ease of string processing at the receiver. Eventually, all the sensor value is combined in a string form and the data is sent to the receiver. Each of the sensor data is collected and converted into string format because most of the data processing during transmitting and receiving of the RF is using string function. Finally, all the sensor is combine/append and transmit to the receiver every one second. Figure 3(b) shows the sensor node with transmitter 1. It measures $\mathrm{PH}$, temperature, humidity and light intensity. The Si7021 temperature and humidity sensor is industrial grade with high precision that can sense temperature and humidity surrounding at paddy field. PH sensor will sense the PH level at the paddy crop and luminosity sensor will sense the level of sunlight for further analysis. 


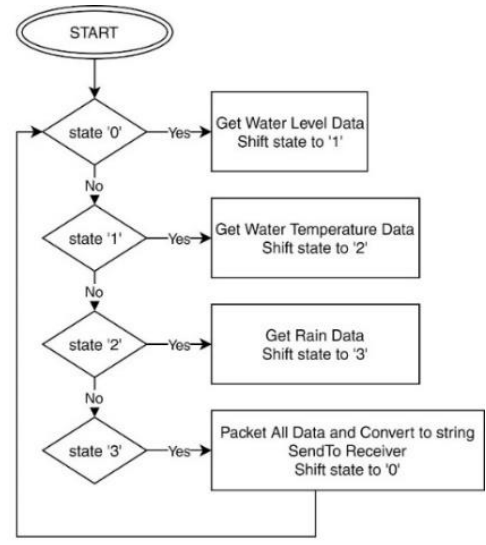

(a)

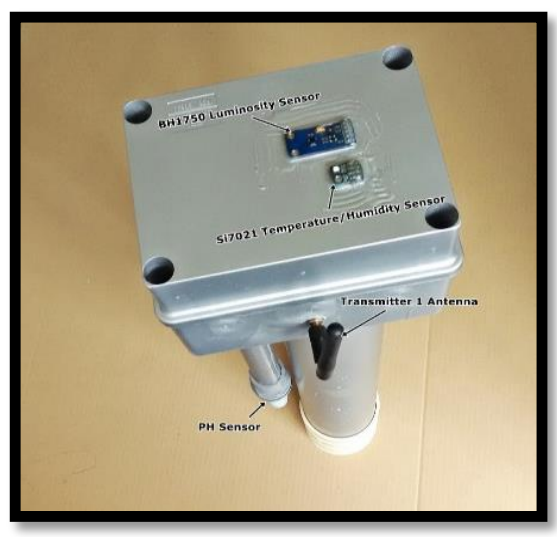

(b)

Figure 3. Sensor node 1: (a) data collection and transmission state (b) physical view

\subsection{Sensor Node 2}

This sensor node consists of rain, DS18B20 water temperature and ultrasonic level sensors. The rain sensor detects the presence of rain to determine the relationship between occurrences of rain. The DS18B20 temperature sensor senses the temperature of water in the water inlet in the paddy field. The ultrasonic sensor detects the water level by measuring water displacements in the paddy field using ultrasonic-based level measurement. Details flow of the sensor node 2 data collection and transmission flow and the sensor node physical view is shown in Figure 4(a) and Figure 4(b) respectively.

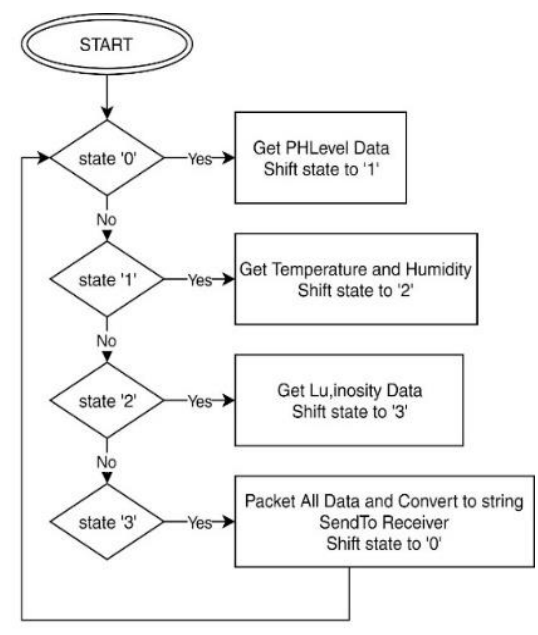

(a)

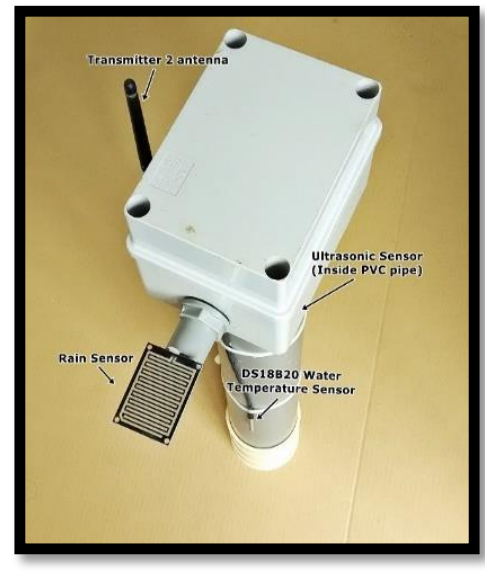

(b)

Figure 4. Sensor node 2: (a) data collection and transmission state (b) physical view

\subsection{Receiver}

The receiver is equipped with a 20x4 character Liquid Crystal Display (LCD). This panel shows the status of the gateway connection. It is also responsible to display the overall communication and data transfer status. This includes the receiver connection status to the $\mathrm{Wi}-\mathrm{Fi}$, data retrieval from the sensor nodes, and data upload to the cloud database.

Figure 5(a) shows the LCD display embedded in the e-PADI gateway system. The gateway has a receiver antenna that receives from the sensor nodes. Figure 5(b) shows the simplified diagram of the receiver/transmission flow of the gateway system. The selection of either data from node 1 or node 2 is multiplexed by using time division multiplexing method. Once the system received data from the sensor nodes (whereby the data collection protocol/procedure has been discussed in previous sections), the gateway transmits the data to the cloud database. 


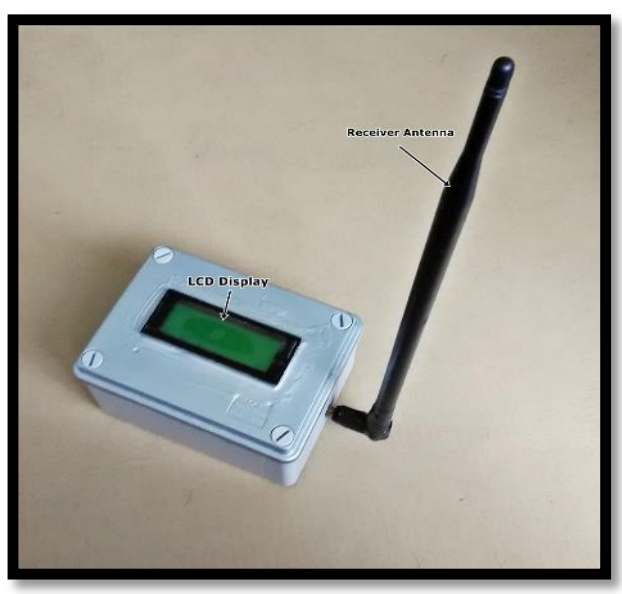

(a)

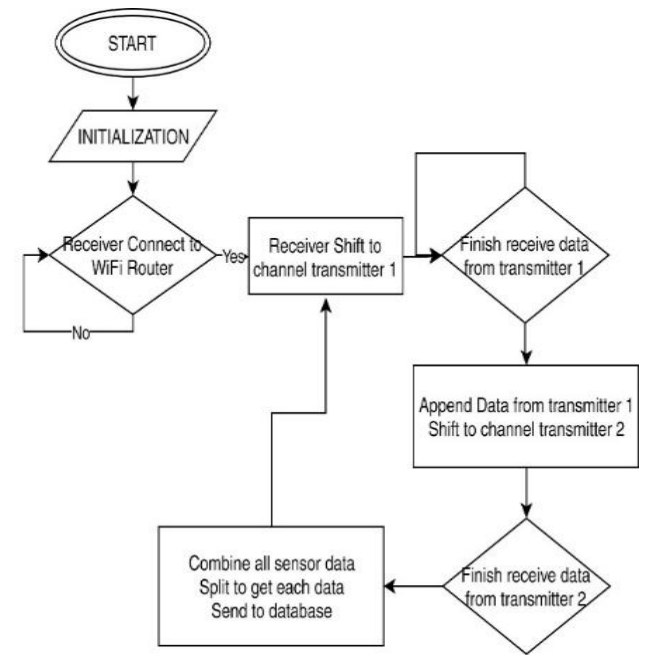

(b)

Figure 5. The e-PADI gateway system: (a) Physical View (b) data receiver/transmission flow

\section{RESULT AND DISCUSSION}

Some experiments have been carried out to the system to verify and validate the overall e-PADI system and operation. The system comprises of three main elements; i.e. the sensor nodes, the gateway and the user application. The following sections explain the experimental results in details.

\subsection{The Sensor Nodes and User Application}

Figure 6 shows data measured from a paddy field. Figure 6(a)-(c) show the user application viewed from a smartphone to access data from sensor node 1. On the other hand, Figure 6(d) shows data from sensor node 2.

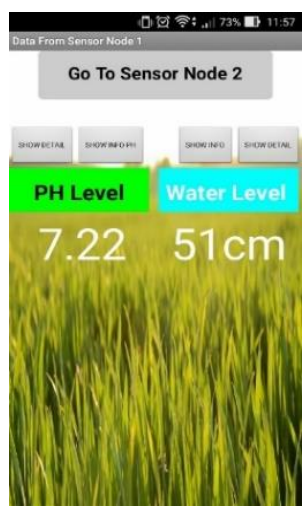

(a)

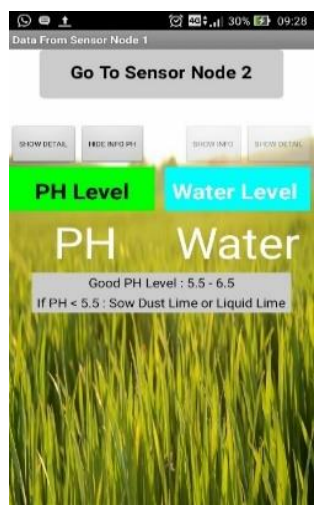

(b)

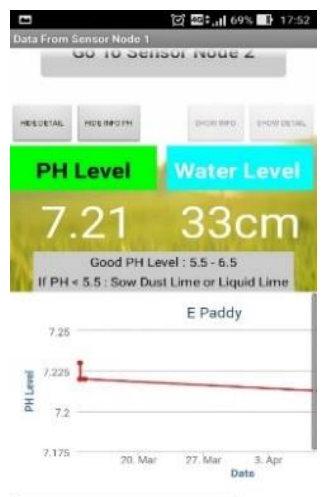

(c)

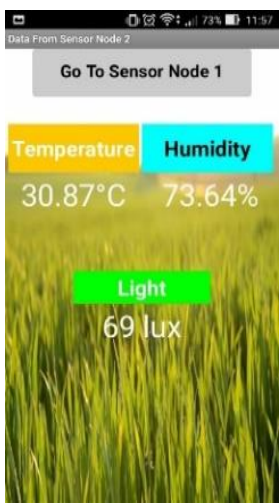

(d)

Figure 6. View from smartphone (a) PH and Water level from sensor node 2. (b) advisory report

(c) Graph of PH levels (d) Temperature, humidity and light measured from sensor node 2

The developed application software is smartphone compatible (for android users). The PH sensor graph is shown in Figure 6(c). It shows the soil acidity levels via graph representation continuously.

\subsection{The Gateway Unit}

Figure 7 shows the gateway unit. It displays the system status i.e. currently (see Figure 7(a)) it successfully received data from both sensor nodes 1 and 2. The gateway system able to scan for various channels to receive data from different sensor nodes; i.e. either node 1 or node 2 . Figure 7(a)-(c) show the progress of the gateway unit until it successfully uploaded sensor nodes data to a database and spreadsheet. 
Once all sensor data has been recorded in the Google spreadsheet, the graph of sensor data can be generated and viewed from the developed user dashboard (can be installed in any device with android-based operating system).

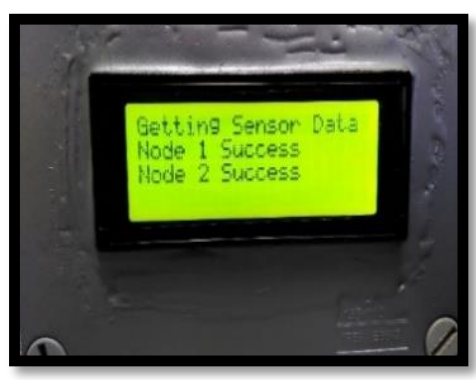

(a)

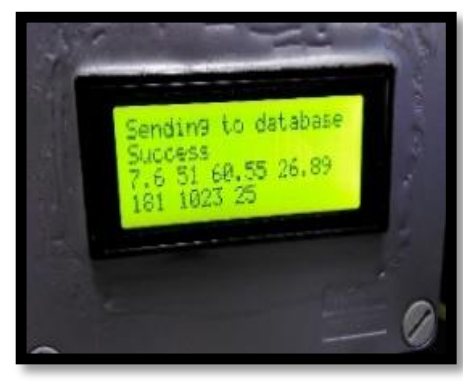

(b)

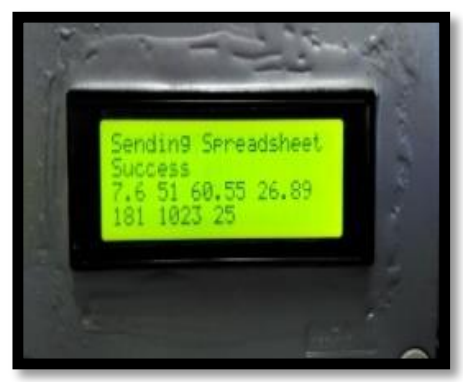

(c)

Figure 7. The gateway unit: (a) Receiving status of both sensor nodes and successfully upload the data to the cloud database. (b) Sending to a database (c) Sending to a spreadsheet

\subsection{Continuous Analysis Mode}

Figure 8 shows results of the soil acidity, humidity and temperature measurement in a paddy field recorded from sensor node 1 .

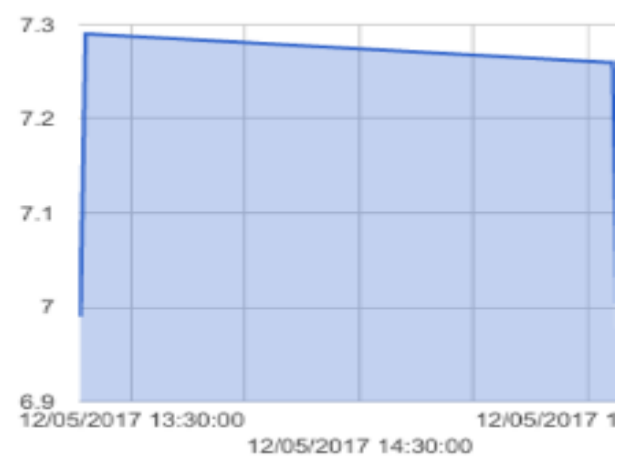

(a)

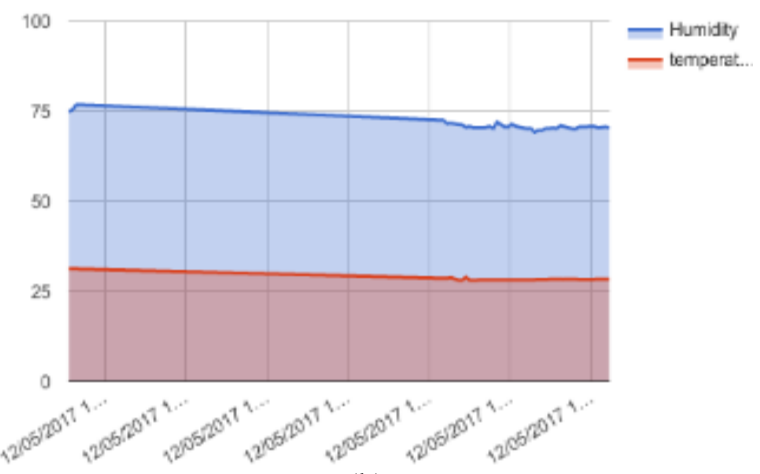

(b)

Figure 8. Continous measurement; (a) soil acidity, (b) paddy field humidity and temperature.

From the graph in Figure 8, it is noted that the average of overall $\mathrm{PH}$ value is 7.24 with minimum $\mathrm{PH}$ value of 6.98 and maximum $\mathrm{PH}$ of 7.9. Based on the e-PADI generated advisory report, $\mathrm{PH}>5.5$ is acceptable and no further action required by the farmer. Similarly for the case of the temperature and humidity of the paddy field. It is acceptable and no advisory report generated by the user application software, however continuous monitoring is still required for better paddy productivity.

\section{CONCLUSION}

An IoT-based paddy monitoring and advisory system named as e-PADI was successfully developed and tested. The system comprised of three main elements; i.e. the sensor nodes, the gateway and the user application software. Unlike other reported IoT-based agriculture work as reported in literature, the developed prototyped offered continuous paddy field environment monitoring with notification and advisory reports. Experimental results had shown that the developed prototyped successfully work and able to continuously monitor paddy development using microcontrollers and sensor nodes with IoT enabled platform. Future works include implementing more sensor nodes and to investigate optimum number of sensor nodes/size of paddy field. 


\section{ACKNOWLEDGEMENTS}

The author would like to acknowledge the support from the Fundamental Research Grant Scheme (FRGS) under a grant number of FRGS/1/2018/TK04/UNIMAP/02/6 from the Ministry of Education Malaysia and an industry grant (9002-00063) from the Malaysian Technical Standards Forum Bhd (MTFSB), the Malaysian Communications and Multimedia Commission (MCMC).

\section{REFERENCES}

[1] Muthayya S1, Sugimoto JD, Montgomery S, Maberly GF. The Sax Institute, Ultimo, Australia. An overview of global rice production, supply, trade, and consumption.Ann N Y Acad Sci. 2014 Sep; 1324:7-14. doi: 10.1111/nyas.12540. Epub 2014 Sep 15.

[2] C. Siwar, N. D. Mohd Idris, M. Y., and G. Morshed, "Issues and Challenges Facing Rice Production and Food Security in the Granary Areas in the East Coast Economic Region (ECER), Malaysia," Applied Sciences, Engineering and Technology, pp. 711-722, Apr. 2013.

[3] Nikos Alexandratos and Jelle Bruinsma. "World Agriculture Towards 2030/2050: The 2012 Revision" Agricultural Development Economics (ESA) The Food and Agriculture Organization of the United Nations Viale delle Terme di Caracalla 00153 Rome, Italy. 2012.

[4] N. Yamaguchi, Y. Sakai, T. Shiraishi, S. Onishi, and T. Kowata, "E-kakashi project, an agri sensor network using ad hoc network technology," in SICE Annual Conference (SICE), 2011 Proceedings of, 2011, pp. 2808-2810.

[5] A. Siuli Roy and S. Bandyopadhyay, "Agro-sense: precision agriculture using sensor-based wireless mesh networks," in Innovations in NGN: Future Network and Services, 2008. K-INGN 2008. First ITU-T Kaleidoscope Academic Conference, 2008, pp. 383-388.

[6] S. Zhiguo, X. Hui, and W. Wensheng, "An architecture for the agricultural machinery intelligent scheduling in cross-regional work based on cloud computing and internet of things," in Computer and Computing Technologies in Agriculture IV, ed: Springer, 2010, pp. 9-15.

[7] S. Li, "Application of the Internet of Things Technology in Precision Agriculture Irrigation Systems," in Computer Science \& Service System (CSSS), 2012 International Conference on, 2012, pp. 1009-1013.

[8] S. Sarangi, J. Umadikar, and S. Kar, "Automation of Agriculture Support Systems using Wisekar: Case study of a crop-disease advisory service," Computers and electronics in agriculture, vol. 122, pp. 200-210, 2016.

[9] M. Grabia, T. Markowski, J. Mruczkiewicz and K. Plec, "Design of a DASH7 low power wireless sensor network for Industry 4.0 applications," 2017 IEEE International Conference on RFID Technology \& Application (RFIDTA), Warsaw, 2017, pp. 254-259. DOI: 10.1109/RFID-TA.2017.8098904

[10] V. Nazarovs, J. Jelinskis, J. Porins, I. Lavrinovica, A. Supe and V. Aispurs, "Architecture and research of M2M wireless mesh networks," 2017 Progress In Electromagnetics Research Symposium - Spring (PIERS), St. Petersburg, 2017, pp. 2500-2503. DOI: 10.1109/PIERS.2017.8262172

[11] G. Ergeerts et al., "DASH7 Alliance Protocol in Monitoring Applications," 2015 10th International Conference on P2P, Parallel, Grid, Cloud and Internet Computing (3PGCIC), Krakow, 2015, pp. 623-628. DOI: 10.1109/3PGCIC.2015.93

[12] M. Weyn, G. Ergeerts, R. Berkvens, B. Wojciechowski and Y. Tabakov, "DASH7 alliance protocol 1.0: Lowpower, mid-range sensor and actuator communication," 2015 IEEE Conference on Standards for Communications and Networking (CSCN), Tokyo, 2015, pp. 54-59. DOI: 10.1109/CSCN.2015.7390420

[13] Mostafa K. Mosleh, Quazi K. Hassan and Ehsan H. Chowdhury. "Application of Remote Sensors in Mapping Rice Area and Forecasting Its Production: A Review”. Sensors 2015, 15(1), 769-791; doi: 10.3390/s150100769

[14] Silicon Laboratories inc. "I2C Humidity and Temperature Sensor". Silicon Lab 2016. Available online. http: silabs.com.

[15] Industrial $\quad \mathrm{pH}$ Available online. https://www.dfrobot.com/wiki/index.php/Industrial_pH_electrode(SKU:FIT0348)

[16] Dallas Semiconductor. "DS18B20 Programmable Resolution 1-Wire Digital Thermometer". Available online: https://cdn.sparkfun.com/datasheets/Sensors/Temp/DS18B20.pdf.

[17] BH1750 Light Intensity Sensor (SKU: SEN0097). Available online: https://www.dfrobot.com/wiki/index.php/Light_Sensor_(SKU: SEN0097).

[18] HC-SR04 user manual. Available online: https://www.mouser.com/ds/2/813/HCSR04-1022824.pdf 